\title{
Deployment Challenges of Offshore Renewable Energy Systems for Sustainability in Developing Countries
}

\author{
Arif Sari $^{1}$, Ali Karaduman ${ }^{2}$, Altay Firat ${ }^{3}$ \\ ${ }^{1}$ The Management Centre of Mediterranean, Nicosia, Cyprus \\ ${ }^{2}$ Department of Accounting Information Systems, School of Applied Sciences, European University of Lefke, \\ Lefke, Cyprus \\ ${ }^{3}$ Department of Geography Teaching, Faculty of Education, Near East University, Nicosia, Cyprus \\ Email: arifsarii@gmail.com, a.karaduman1@hotmail.com, altay.firat@neu.edu.tr
}

Received 20 January 2015; accepted 13 September 2015; published 16 September 2015

Copyright (C) 2015 by authors and Scientific Research Publishing Inc.

This work is licensed under the Creative Commons Attribution International License (CC BY).

http://creativecommons.org/licenses/by/4.0/

(c) (i) Open Access

\section{Abstract}

This research aims to expose deployment challenges of offshore renewable energy systems in developing countries. The investigation of the deployment model covers climate conditions, economic conditions, necessary infrastructure services and wind power by considering the case of Cyprus Island which is one of the Small Island Developing States (SIDS) countries. The convenience of Offshore Energy Systems to the territory and their systematic proper work is an important issue. Because of that, the setting up of Offshore Wind Energy Tribunes in Cyprus, the planning process, structuring of cost values and necessary resources, the investigation of the geographic conditions for obtaining the energy flow and assessment of these conditions for offshore Wind Tribunes are the prime objectives of this study. The orientation period and the applicable qualifications of the offshore energy systems were evaluated on the basis of the world wide references. The study is concluded by the estimation of the advantages and disadvantages of the system for Cyprus.

\section{Keywords}

Renewable Energy, Offshore Renewable Energy Systems, Sustainability, Small Island Developing States, Cyprus

\section{Introduction}

A condition of the globalized world creates a depression for the countries from the point of energy resources.

How to cite this paper: Sari, A., Karaduman, A. and Firat, A. (2015) Deployment Challenges of Offshore Renewable Energy Systems for Sustainability in Developing Countries. Journal of Geographic Information System, 7, 465-477. 
Limitedness of the world energy resources caused the world countries to seek for new energy resources. As a result of the researches, renewable energy resources were found. The world countries leastwise tried to satisfy the demand for energy with the use of these resources. One of these renewable energy sources is the wind. This study gives coverage to wind energy. When this type of energy produced by the wind's blowing power is used in a correct way, it was seen that it supplies the energy necessary. For instance, according to 2003 data, $6 \%$ of Germany's energy demand, 4\% - 5\% of Spain's energy demand, 20\% of Denmark's energy demand and less than $1 \%$ of USA's energy demand were supplied from wind [1]. Offshore Wind Turbines are stated as one of the wind energy systems. Offshore wind turbines generate electricity from offshore winds.

A country-based classification of developing countries can be useful in order to determine the status of the utilization of offshore wind turbines in developing island countries.

There are 41 developing island countries worldwide. Some of these countries are Fijis, Samoa, Vanuatu, Maldives, Sao Tome, Seychelles, Bahamas, Barbados, Cuba, Dominican Republic, Grenada, Haiti, Saint Lucia, Saint Vincent and Grenadines, Trinidad, Malta and Cyprus. Island countries have energy demand problems due to their nature of economic, geography and human based characteristics.

In this research, the installation process of Offshore Energy Turbines, which is stated as one of the offshore wind energy systems in island countries will be held and the inconveniency facts of the installation process will be evaluated.

In this study, the installation of Offshore Energy Turbines in Cyprus, which is one of the Mediterranean developing island countries, and the qualifying conditions for the installation, will be investigated.

\section{Developing Island Countries and Their Problems}

A lot of developed and developing countries recognized the risk of depletion of energy resources. This awareness directed the developed and developing countries to the use of renewable energy.

Renewable (sustainable) energy resources embody biomass, biogas, solar, wind, tide, wave energy resources. These energy resources came into use with the preparation of the adaptation of infrastructure of most developed countries. However, over forty developing island countries have been facing problems with making use of these energy resources. According to necessary researches, the main problem is based on economical and the second one is the economic budget for energy demands.

Natural sources, historical and touristic places stand out when the economic conditions of the island countries are investigated.

The importation margins of island countries for petroleum as fuel and gas are increasing constantly.

For instance, one of the developing island countries-Malta's importation for coal tar and crude petroleum within 2010 is stated as $\$ 129,929,266$. It brings up to mind that increases in the importation margins are due to the fluctuation of the world economy [2].

The prime minister of the Cook Islands announced that in the margin of importation for island's energy importation, $15 \%$ of the gross national product has exceeded 15 million USD and suggested the renewable energy sources, biomass, wind, solar, ocean, wave, hydroelectric and geothermal energies as an alternative to this effect. Other developing island countries, such as Haiti, Mauritius, Seychelles, Comoros and Cape, announced in the "Aims and Politics" program that they are aiming to develop the renewable energy sources [3].

The examples mentioned above state clearly that the expenses of fossil fuels (oil, coal, etc.) have caused these countries to redirect to renewable energy sources.

Energy demand grows nearly $1.5 \%$ every year. Present electric infrastructure and lots of power plants are close to expiring. There will be a 900,000,000,000 € need of investment for new energy production capacity within the next 25 years [4].

\section{Offshore Renewable Energy Systems}

The operational analysis of offshore energy system; component and parts of wind turbines and working principles are stated below.

The terms below are commonly used for all wind turbines:

- Hub Height: Defines the elevation of the hub from the ground.

- Swept Area: Defines the area swept by the rotor disc.

- Tip Speed Ratio: Defines the ratio of the wing tip speed to the wind speed. 
- Output Power: Defines the continuous output power in electrical uses.

- The main components of wind turbines used in electric production are; rotor wings, brake system, yaw system, transmission system, generator and tower [5]. Each component explained separately in the following subsections of this section.

\subsection{Tower}

Material of the tower is generally steel or concrete. Modern wind turbines have circular cross section towers. The height of the tower is optimized with the yield of the higher winds and the cost of the tower increasing with the height. Another parameter for the height, the natural frequency of the tower depends on the material and effects the cost. 11\% - 20\% of the cost of a wind turbine goes to tower [5] (Figure 1).

\subsection{Turbine Rotor}

The rotor of the wind turbines are produced from aluminum, titanium, steel, fiber reinforced plastics (fiberglass, carbon fiber and aramid fiber) and wood. Nearly all of the modern wind turbine wings are produced with fiberglass reinforced polyester or epoxy. Resistance to bending of wings made of steel is very high but they have problems like fatigue strength or corrosion. Aluminum wings are lighter, they have better fatigue strength and they are more resistant to corrosion, but their production is hard, her are expensive and they can be buckled [5].

Components of the turbine, which are shown on Figure 2, are listed below:

1. Hub

2. Wings

3. Hydraulic Station

4. YAW System

5. YAW System Control Gears

6. Gearbox

7. Brake Disc

8. Generator Coupling

9. Generator

10. Vibration Sensor

11. Anemometer

12. Wind Direction Sensor

13. Bottom Housing

14. Top Housing

15. YAW System Main Gear

16. YAW System Brake Disc

17. YAW System Calibration

18. Cable Interconnection Element

19. Tower

[6]

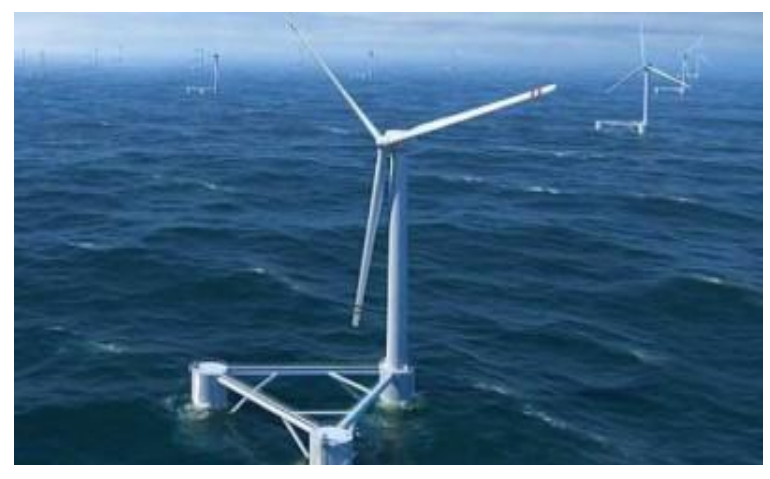

Figure 1. Tower. 


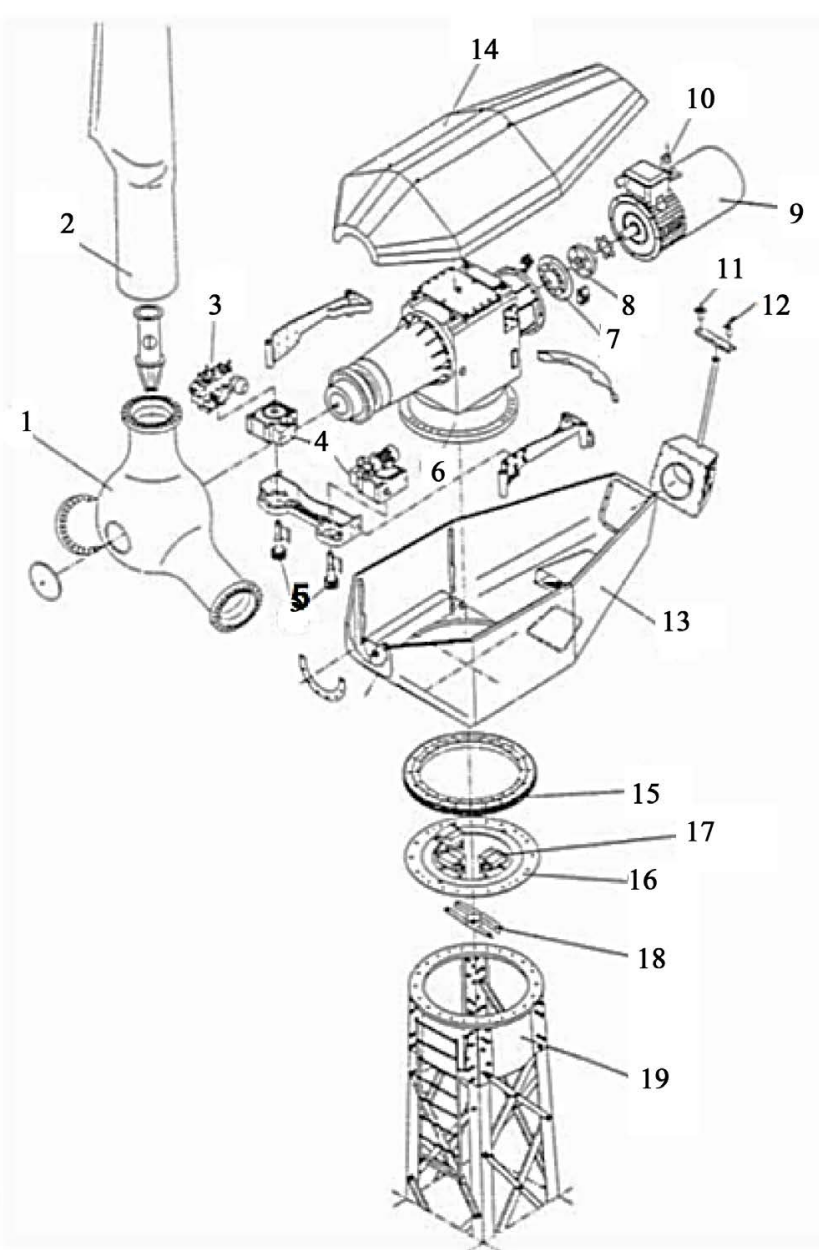

Figure 2. Components of turbine.

\subsection{Gearbox}

Angular velocity $\omega$ of the rotor is generally not enough to produce move the generator fast enough to create the needed electrical frequencies. Gearbox can increase or decrease the rotation speed. In wind turbines, gearboxes are used in converting the motion of a low speed shaft to a high speed shaft motion, which is connected to generator. For a lot of applications, gearboxes react to the gap between two gears. Driving gear rotates for an angle before contacting the opposing gear. This results in the fact that opposing gear doesn't rotate before the angular rotation of the driving gear finishes. In the model of gearbox used in this study, the behavior of the gears is idealized. Input parameters for the gearbox are the angular velocity and torque of the low-speed shaft connecting gearbox and rotor [5]. The gearbox is shown on Figure 3.

\subsection{Generator}

Generators used in the wind energy plants can be alternating current generators or direct current generators. Even if the current obtained here is unqualified direct or alternating current, it can be tempered for the grid with the use of power electronics apparatus. Direct current generators must are not preferred in high power wind energy plants because they need frequent maintenance and they are more expensive in comparison with alternating current generators. At present time, they are used in small scale wind energy plants for energy storage purposes. For the sake of avoiding the noise and lowering the gear losses, turbines with multipolar generators and no gearboxes are used.

E-40 Wind turbines with no gearbox, installed with the auto producer system in Germany, produced by German company Enercon, has 84 polarities and they exceed a nominal power of $500 \mathrm{~kW}$ in case their shaft rotates 


\section{8 cycles in a minute.}

In grid connected alternating current generators, an electrical energy providing the grid frequency is produced. That means benefiting from wind turbine in an optimum speed such as $8 \mathrm{~m} / \mathrm{s}$. For that reason, in some of the wind turbines, there are two separate generators for low and high wind velocities [5]. A generator and mechanic interface is illustrated on Figure 4.

From the statements above, it can be deduced that the most important tool for electric generation from wind is the wind turbines. A generator is used to convert the kinetic energy of the wind into electricity. Wings, just as in the vapor turbines, run generator which produces electricity. As the wind passes through the rotor, an aerodynamic lifting power emanates and spins the rotor.

One of the world wide known energy companies, Siemens' predictions for the offshore generator power specifications stated in Table 1.

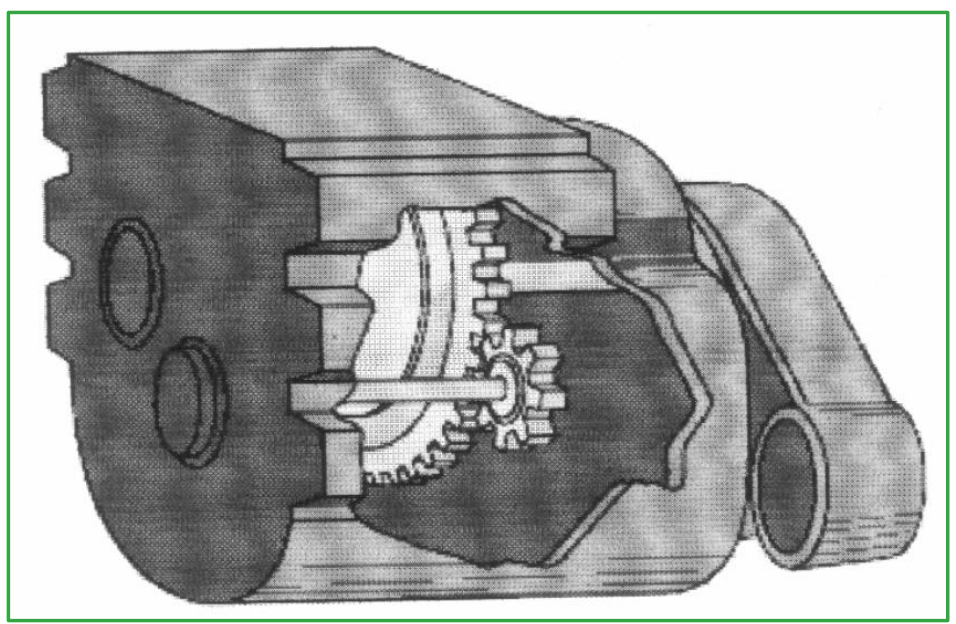

Figure 3. Gearbox.

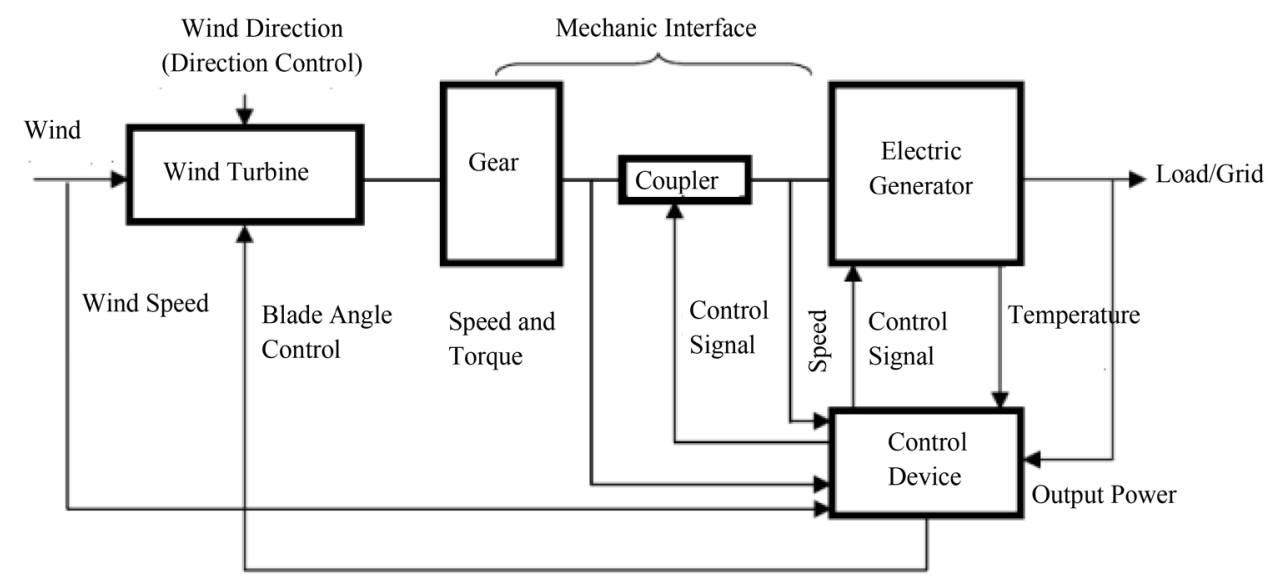

Figure 4. Generator.

Table 1. Siemens generator specifications.

\begin{tabular}{cc}
\hline & Generator \\
\hline Type & Asynchronous \\
\hline Nominal Power & $3600 \mathrm{~kW}$ \\
Voltage & $690 \mathrm{~V}$ \\
Cooling System & Integrated Heat Exchanger \\
\hline
\end{tabular}


This wind turbine they produced is open for use in Germany and Denmark. The facility which is supposed as the largest offshore wind power plant of Denmark is opened by Siemens at 04 September 2013. There are 111 wind turbines in the plant, producing $400 \mathrm{MW}$ power. $400 \mathrm{MW}$ electric power which will be produced by 111 wind turbines will meet 1/4 of the energy demand of Denmark, namely 400,000 houses electric demand [7].

The development of design standards for offshore wind energy systems:

- Integrated environment status and design parameters,

- Address energy transmission and grid interconnection issues,

- High levels of wind system availability and performance through optimized approaches to operations and maintenance,

- Tailor support structure designs to site specific conditions.

The above mentioned items lead to developments in the design [8].

Offshore wind energy made the fastest development among all energy systems. First offshore turbines were installed in 1991. There are 308 offshore turbines in European Union (EU) valuing 2.6 billion Euros. Nine separate offshore plants power is $883 \mathrm{MW}$. It is thought that there will be $2.3-2.944 \mathrm{MW}$ turbines at Norway coasts by the end of 2010 [9].

\section{Wind Energy in Offshore Renewable Energy Systems}

The fact that installed capacity of wind turbines has reached MW levels, the high wind potential of seas and rapid development of the installation technologies brought up offshore applications to the agenda. It is believed that the life span of offshore plants can be between 25 - 30 years due to the difference of turbulence density between soil and offshore and having lower turbulence offshore. At the first stage, places with up to $10 \mathrm{~km}$ distance from the coast and with a depth less than $10 \mathrm{~m}$ are targeted. First offshore wind farm is the $5 \mathrm{MW}$ Vinde by wind farm installed near Lolland, Denmark.

World Wind Energy Association (WWEA), predicts that by the end of 2010, the installed wind power capacity will reach $160 \mathrm{GW}$. It is announced that this capacity will reach $445 \mathrm{GW}$ by the end of 2016 [6].

Under the scope of the information stated above, the efficiency of wind is higher in open seas. Although this fact cannot be correlated to all countries in all circumstances while open sea wind efficiency may change due to effects of the ocean. For instance, the abrupt changes in the airstream may cause long-termed storms [10].

There are a lot of future planned offshore wind farms:

- The Netherlands Ministry of Infrastructure and Environment,

- German Federal Maritime Hydrographic Agency,

- British Royal Estate,

- Norway Water Resources and Energy Directorate,

- Denmark LINDOE Offshore Renewables Center,

- Belgium Management Unit North Sea Mathematical Models.

The world's largest offshore wind plant is in Denmark. The new plants installed at Baltic Sea are examples of that.

European Wind Integration Study (EWIS) 2015:

EWIS study showed that the costs of integrating wind power (with the operation of flexible generation means) are relatively small in comparison with the benefits in terms of fuels and $\mathrm{CO}_{2}$. The cut of wind power output is very small (around 0.03\%) at targeted year 2015 .

Demand side management, offshore grids and new storage facilities are also contributing to a better wind integration in the future [10].

\section{Major Deployment Challenges of Offshore Renewable Energy Systems}

For developing island countries, the reason that offshore wind turbines cannot be installed is considered as economic inadequacy and lack of infrastructure. Cyprus is an example of these countries. When investigated, tourism can be considered as the main source of income in the developing island countries. Due to their geographical locations, utilization of renewable energy systems after infrastructural investments can be possible.

With regard to economic specifications, as an instance:

Malta: The economy of Malta who has no heavy industry and no natural resources, is tender and intensifies on electronic, medicine, banking and tourism sectors. Agriculture isn’t developed because of water issues. Rate of 
unemployment in 2009 was announced as 7.1\%. Rate of inflation was $1.8 \%$ in 2009. Primary imported goods are textiles, livestock, food, machinery. Exportation goods are finished textiles [11].

Importation and Exportation Data: (year 2011)

Importation: 3066.2 (Million Euros)

Exportation: 1656.6 (Million Euros)

[2]

As it can be seen in the Malta example, the major problem of the developing island countries is the economic imbalance. It is believed that there is a shoestring budget for offshore wind tribune constructions due to economic imbalance.

Observing the turbine costs, only the imported generator costs of the planned wind energy turbine installations are $\$ 54,345.70$ in 2006. Germany is ranked as the first for importation. Only footings and towers are made in Turkey. Turbine costs are still very high and this seems to be the major problem [12].

Continuing the economic assessment, generally speaking, developing island countries does not have the financial infrastructure for installing renewable energy plants [13].

The installation periods are extended due to the inability to find the infrastructure companies to provide the necessary technology [13].

Turbine Maintenance Period:

Modern wind turbines are designed to work for 120,000 hours in their 20 year lifetime. This period is much longer then the life time of an automobile which is 4000 - 6000 working hours. Practical experiences show that the maintenance costs are lowered in the new turbines. An individual turbines maintenance costs are much more than the average maintenance cost of the turbines in a wind park. Some wind turbine components experience changing and breaking down more than the others. These facts are seen especially on in rotor blades and gearbox. Generator, gearbox and rotor blades make up the $15 \%-20 \%$ of the turbine costs [6].

\section{Requirements for Deployment of Offshore Wind Energy Turbines}

Offshore wind parks must be installed in special economic areas with a defined distance from the coast. They experience severe conditions due to $40 \mathrm{~km}$ - $100 \mathrm{~km}$ distance from the coast. They experience dynamic loads, heavy static loads and salted waters for at least 20 years of life span in their installation regions with a depth of $20 \mathrm{~m}-50 \mathrm{~m}$. The projection is made for $50 \mathrm{~m}$ of wave height. Besides these factors, ice mass, earthquakes and ship accidents also must be taken into consideration. With the effect of the waves, high speed fluctuations at the bottom of the sea may occur, leading to subsea gravitations under the foundation of the turbine. The dimensions of these gravitations are unpredictable. This uncertainty creates the need for a solution inhibiting whole formations under the foundations of offshore wind turbines [14]. The Wind Turbine is illustrated on Figure 5.

Installed offshore turbines and their specifications:

1) Helgoland, DE-years 1989-95-1/1200 k/W - $1.2 \mathrm{~m} / \mathrm{W}$,

2) Blekinge, SW-year $1990-1 / 220 \mathrm{k} / \mathrm{W}-0.22 \mathrm{~m} / \mathrm{W}$,

3) Vindeby, DK-year 1991-11/450 k/W - $4.95 \mathrm{~m} / \mathrm{W}$,

4) Lely, NL-year $1994-4 / 500 \mathrm{k} / \mathrm{W}-2 \mathrm{~m} / \mathrm{W}$,

5) Tuno, DK-year 1995-10/500 k/W - $5 \mathrm{~m} / \mathrm{W}$,

6) Dronten, NL-year 1996-19/600 k/W - $11.4 \mathrm{k} / \mathrm{W}$.

Early installed offshore wind turbine instances are given above [15].

\section{A Small Island Developing State Country: Cyprus}

Cyprus is located at the north eastern area of the East Mediterranean basin in between $34^{\circ} 33^{\prime}-35^{\circ} 34^{\prime}$ northern latitudes and $32^{\circ} 16^{\prime}-34^{\circ} 37^{\prime}$ eastern longitudes. It is the third largest island of Mediterranean after Sicilia and Sardinia with its $9.251 \mathrm{~km}^{2}$ surface area. The length of the island is nearly $224 \mathrm{~km}$ and the width is $96 \mathrm{~km}$ at its maximum. Its neighbor to Turkey in the north $(60 \mathrm{~km})$, Syria in the east (96 km), Egypt in the south (385 km) and Greece in the west (380 km Rhodes) besides Israel and Lebanon (Figure 6).

As a result of its geographic location, there is an intense Mediterranean climate dominant in the north side of the island in which summers are arid and hot, winters are mildly cold. Summer and winter seasons are separated with short springs and short autumns. However, two mountain chains (Trodos in the south and Besparmak in the north), cause important climate changes. While the Besparmak Mountain Chains experience nearly $550 \mathrm{~mm}$ 


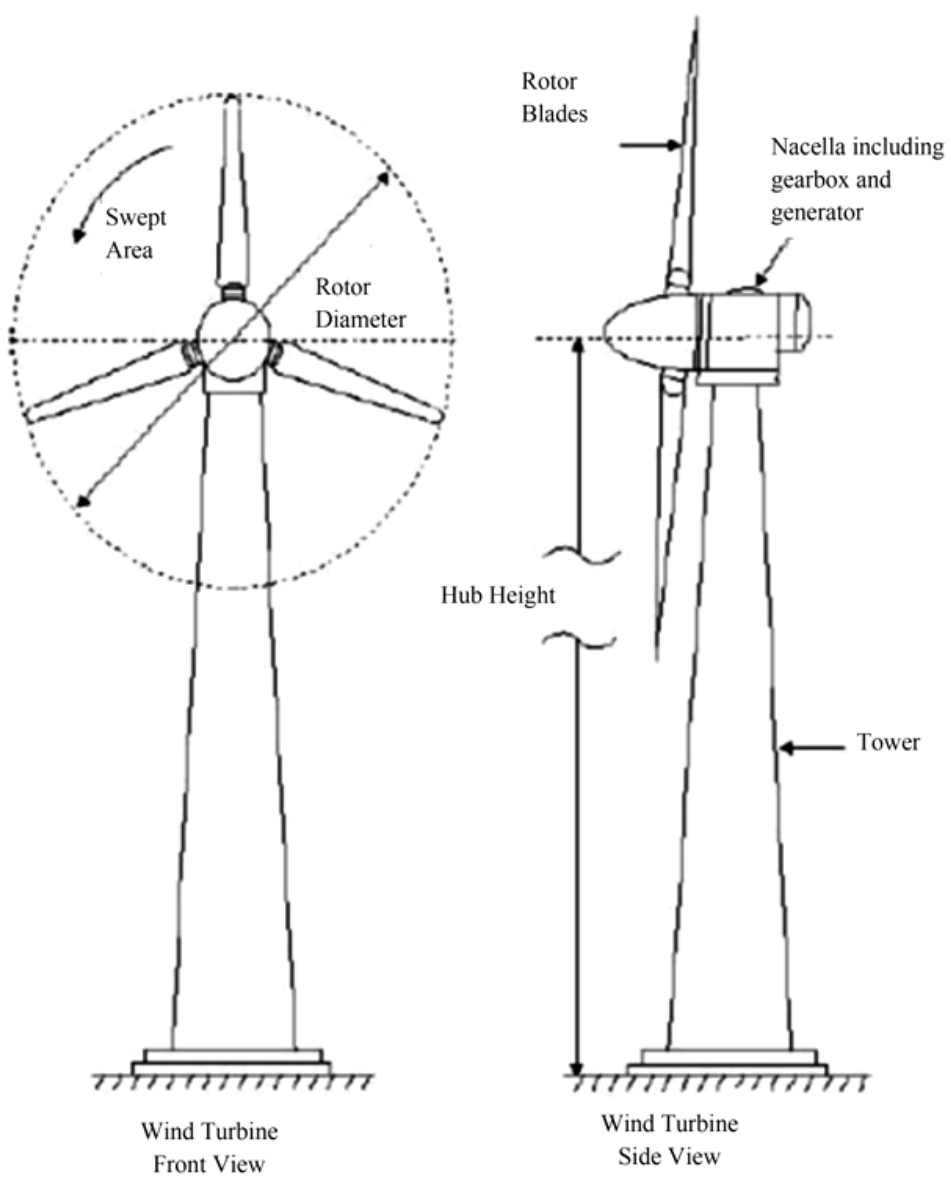

Figure 5. Wind turbine.

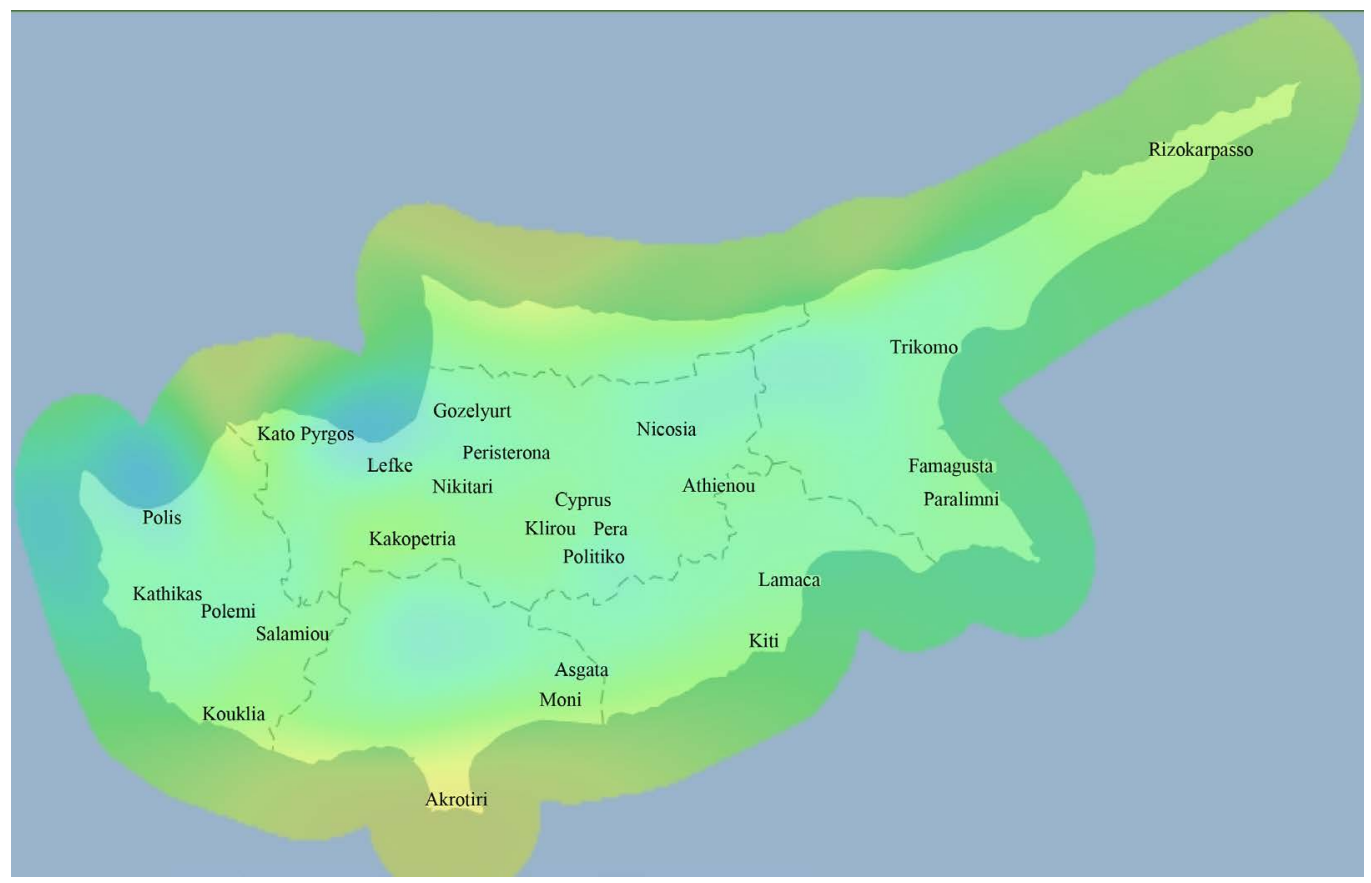

Figure 6. Cyprus map. 
rainfall, some regions of Mesarya plains experience a lower amount of rainfall (300 - $350 \mathrm{~mm}$ ) yearly, summer season is hotter in this regions. Amount of the rainfall increases as the distance to the mountains decreases. In the coastal regions with a larger atmospheric humidity and relatively low temperature differences has a less intense climate in contrast to the interiors [16].

Agriculture and agriculture based industry has an important place in Cyprus economy. Agriculture sector, holding a critical place in the social-economic structure of the country, might be counted as the leading sector of the economy. 4.8\% (4332) of the population is employed in the Agriculture sector. This sector leads in the bank credits with $0.47 \%$, in the exportation as raw materials with $29.40 \%$ and as processed agricultural goods with $45.70 \%$.

The country possesses a total amount of 2,465,552 decares of land. 1,398,123 decares of this land (56.7\% of the total area) can be used for agricultural purposes. $60.9 \%$ of this area, meaning 852,665 decares can be used economically for agricultural purposes, 780,132 decares of it for dryland farming and 72,532 decares for irrigated farming [17].

In Cyprus, animal husbandry activities are largely domestic market oriented, small scale and for the family demands in the countryside. There is a total number of 204,546 animals which are distributed to distinct as; 36,460 in Nicosia, 61,990 in Famagusta, 34,706 in Kyrenia, 28,071 in Morphou and 43,319 in Trikomo region [18].

\subsection{Renewable Energy Resources in Cyprus}

Available renewables in Cyprus are; Biomass, Biogas, Solar Energy, Wind Energy, Wave Energy and Tide Energy.

Biomass Energy: Biomass is the biological basis non-fossil organic matter. All of the organic matter with animal or plant origin having the main ingredient of carbohydrate compounds are defined as biomass energy source. The energy gathered from these sources is called biomass energy [19].

Biogas Energy: Biogas, is a mixture burning with a bright blue flame including $54 \%-80 \%$ methane $\left(\mathrm{CH}_{4}\right)$ and $20 \%-46 \%$ carbon dioxide $\left(\mathrm{CO}_{2}\right)$. It is released by the anaerobic fermentation of the organic matter; it is colorless, odorless and lighter than air with a 0.83 density and 110 octane number. Biogas is the produced version of natural gas. Natural gas is also a type of biogas which is released in an airless medium under the rocks [20].

Solar Energy: Solar energy is a renewable energy source coming from the sun with a constant intensity of $1370 \mathrm{~W} / \mathrm{m}^{2}$ outside the atmosphere and with a non-constant intensity between $0-1100 \mathrm{~W} / \mathrm{m}^{2}$ inside the atmosphere. It can be used in warming, cooling and electric generation.

Wind Energy: Energy produced from wind classified as kinetic energy due to its speed. Wind turbine is the system that converts the kinetic energy of the wind into mechanical energy, and then converts the mechanic energy into electrical energy. A wind turbine consists of tower, generator, gearbox, electric-electronic components and rotor. Kinetic energy of the wind is converted into mechanical energy by rotor. Rotation of the rotor shaft is transmitted to the generator, with a speeding up process. The electrical energy generated by the generator is stored in the batteries and supplied to the consumers.

Wave Energy: Ocean waves are a huge source of energy without pollutant effects. However, this energy source is ignored for years. It is calculated that the power which can be gathered from the waves that are created with the blow of the wind on the surface of the seas, is 10 - 15 times greater than the energy that could be gathered from other sources. It could be useful in case it is achieved to be used.

Tide Energy: It occurs as a result of the gravitational forces between The Earth, The Moon and The Sun. Energy can be produced in the tide event from the motion of water in two ways. The first and the oldest one is collecting the water in a reservoir in order to create an elevation difference between the water and the sea level and turning this potential energy into electrical energy. Disadvantages of this method are the costs and the need for space. Second method is making the water turn the turbines during the ascending and descending motions. Energy can be produced from the water movements during tides in two methods. Electricity is produced by the generator fed by the turbine by gathering water in a chamber [21].

\subsection{Deployment Challenges of Offshore Wind Turbines in Cyprus}

There are reasons that offshore wind energy systems are not suitable for installation in Cyprus. These reasons 
can be classified as economic problems, geographic problems and infrastructure problems. Considering the economic problems in our study, there seems to be budget problems. As an addition, when considering the geographic conditions, it can be seen that wind power is inefficient. Additionally, one of the mains reasons that these systems cannot be installed is that the industrialization of Cyprus is based on agricultural and consumables. The deployment problems are categorized into 3 different countries as economic, geographic and infrastructural problems and explained separately in the following subsections.

\subsubsection{Economic Problems}

Considering the economic structure of Cyprus, it can be seen that it is configured by Tourism, Education and Agriculture.

Economy data for year 2013 are:

- GDP (Million \$): 4,107.4

- Real Economic Growth Rate (\%): 2.0

- GDP per capita (\$): 15,622

- Inflation Rate (\%): 10.2

- Budgetary Deficit (Millions): -411

- Number of Foreign Tourists: 1,232,753

Dealing with the data above, it is observed that gross domestic product is low and it is not able to bear the expanses for investments. Besides, low real economic growth rate is remarkable. Originating from the increase in the inflammation rate, surplus of the importation payments in the budget and presence of budgetary deficit might be counted as obstacles for investments. Under these conditions, the fact that the project is not state funded troubles the investors. This can be counted as another economic problem [22].

Importation and Exportation Data for 2013:

Importation (Million \$): 1,699.4

Exportation (Million \$): 120.7

Balance: $-1,578.7$

Imbalance between importation and exportation is one of the reasons that the turbine installations cannot be implemented. According to Energy Institute's announcement, President of Germany Angele Merkel brought the first wind energy plant in Baltic Sea into service. According to the project data, plant includes 21 turbines with a distance of $16 \mathrm{~km}$. Minister of the Environment announced that nearly 1.2 Million Euros of the budget is allocated. Regarding to the difference between Cyprus' budget and GDP and the Germany reference, it can be deduced that for Cyprus to install offshore wind turbines seems hard in the near time.

\subsubsection{Geographic Problems}

Considering the Mediterranean winds, the southwester, the south wind and the southeaster are the dominant winds that blow in a certain direction. The map is generated in order to expose possible wind direction in the northern part of the island. The annual average wind map for Cyprus is given on Figure 7.

The figure above illustrates the wind speed which is given for the particular regions of the island. In addition to this, the wind rose is separately designed and illustrated on Figure 8.

The Southwester: Hot wind blowing from south west direction in the west region of Turkey. Sometimes its speed can exceed to 40 - 60 Knots. It is very important for sailors. It causes a hot weather after the rain.

Especially in winter season, it can cause floods, overflows and inundations by melting the snow. It is a wind causing the temperature to rise more than normal when blowing. From time to time it affects the marine transportation in The Aegean Sea, The West Mediterranean Sea and The Marmara Sea, unsecure life and property.

The Southeaster: A dry and hot wind blowing from south east and named by local sailors. It dries the air and causes the temperatures rise in the locations it affects. It's not an intense wind.

The South Wind: An extremely hot and humid wind blowing from the south. The cyclones occurring in the middle of the Mediterranean are the factors for the observation of this kind of winds. It's not an intense wind [23].

The reasons that there are no winds around Cyprus Island that are strong enough for wind turbines, Cyprus' continental shelf problems, activity of Mediterranean Fault line and the fact that waves are not strong enough, does not support the installation of offshore wind plants. 


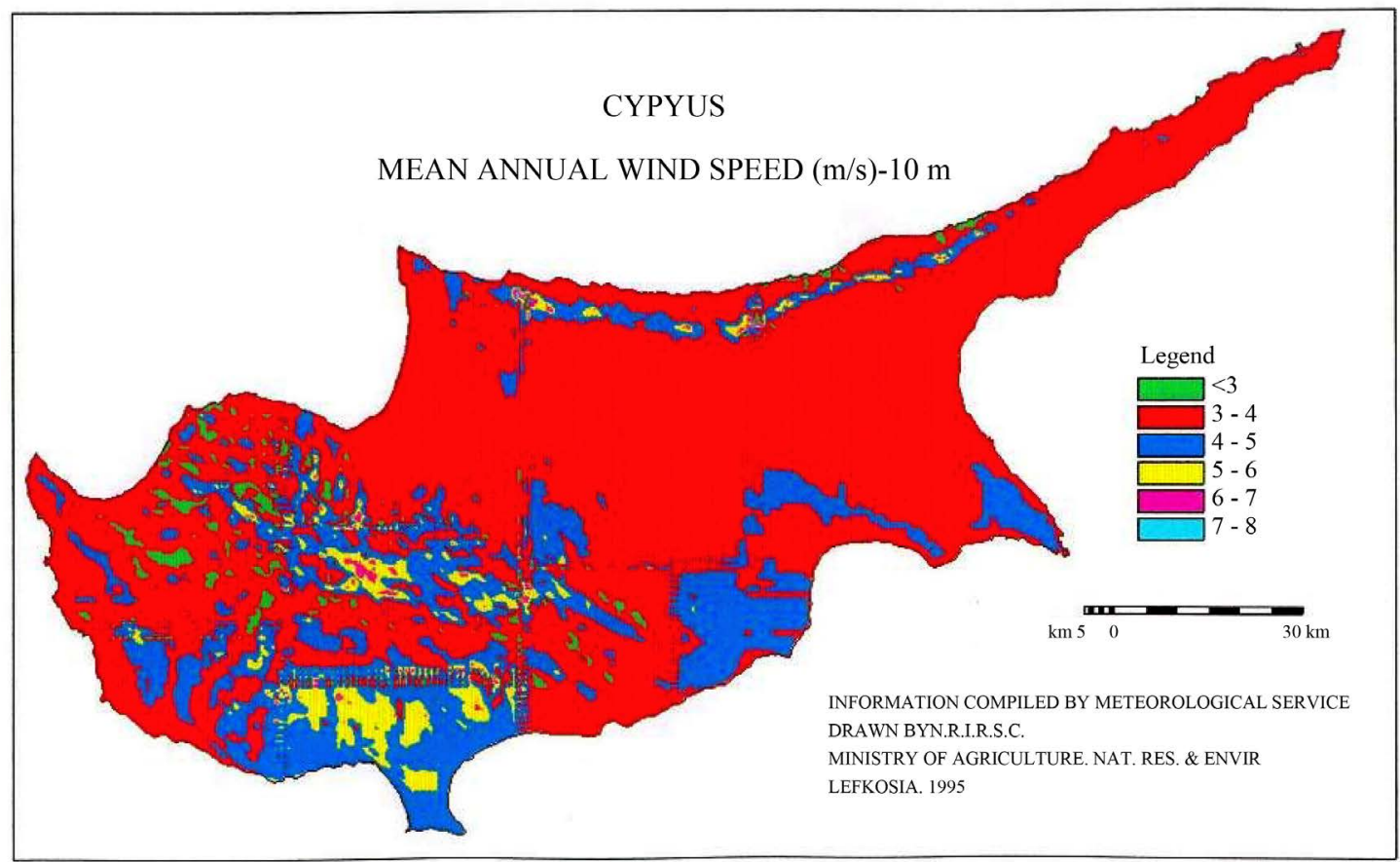

Figure 7. Annual average wind speed map of Cyprus.

\section{TRNC Wind rose (2012)}

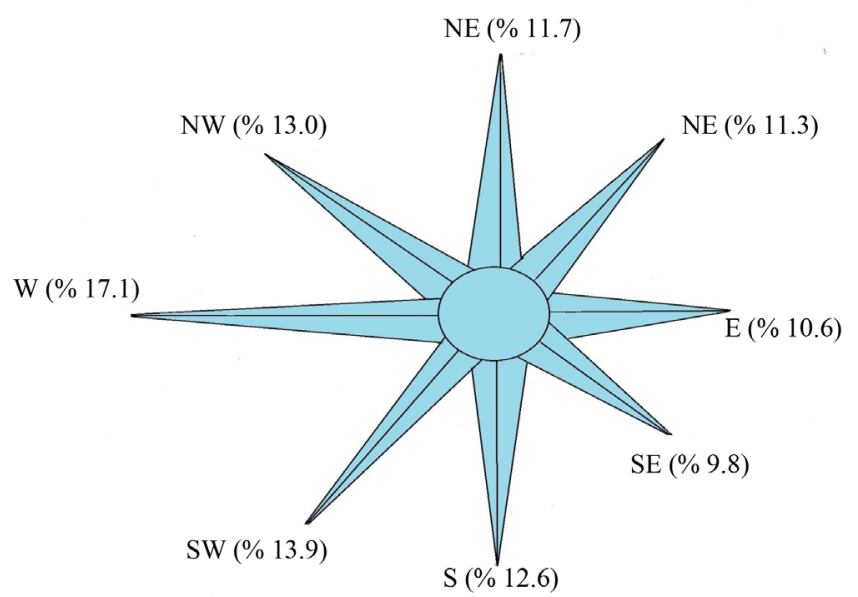

Figure 8. Northern Cyprus wind rose.

\subsubsection{Infrastructural Problems}

Besides taking into account the above mentioned economic data, the sustainability of the renewable energy systems in Cyprus will be interpreted with the present industrialization data of the island. Income from industry is lower than the income from tourism and education.

According to the findings of the research conducted, industrial facilities need energy. All of the manufacturing industry branches in the country use electrical energy. Since there are no rivers in the country, all the energy is produced from fuel-oil which is imported from other countries. The fact that the energy raw material is bought from abroad and the transportation costs are high inhibits the development of the industry. Marketing situation of the finished products produced in the manufacturing plants affect the development of the industry. Generally, the products are marketed inside the country. The cost of these products is generally high because the industry relies on outside raw materials and energy. This situation causes the size of the domestic market decrease. Under 
these conditions, only a small portion of the finished products can be exported. The financial problems of the country seem to be an obstacle for the installation of huge industrial facilities. The capital stock is not enough for constituting the conditions needed for industry, conducting transportation and marketing services in a regular way, paying the salaries of the workers and pursuing the technological developments.

Generally looking, it can be seen that industry is branched in food, drink, tobacco, forest products and furniture, paper, paper products and printing, chemicals, oil, rubber and plastics, soil, metal, metal products sectors [24].

As it is understood, facts that Cyprus industry is based on consumer products and there are not enough infrastructures for energy facilities are the obstacles for offshore wind turbines installation in Cyprus.

\section{Conclusion}

With our investigations and with the help of the data we have, it is understood that renewable energy sources are very important for developing island countries. However, these energy resources must be implemented in the correct time and correct place with right investigations and suitable strategies. For the installation of renewable energy plants, they should not be working for a period of time, and on the contrary they must work continual situation. Needed financial statements, annual budgets and country resources must be investigated carefully. Within this research, it is observed that, offshore wind turbines installation is high in costs, infrastructure is insufficient and geographic conditions are unfavorable.

\section{Conflicts of Interest}

The author declares no conflict of interest.

\section{References}

[1] Güler, Ö. (2005) Wind Energy in the World and Turkey. Istanbul Technical University, Institute of Energy, 213. http://www.emo.org.tr/ekler/58072be2820e868_ek.pdf

[2] Malta Country Bulletin (2011). http://www.corlutso.org.tr/uploads/docs/malta ulke raporu.pdf

[3] Renewable Energy Potential of Small Island States (2008).

[4] EWA (2007) Delivering Offshore Wind Power in Europe. Policy Recommendations for Large-Scale Deployment of Offshore Wind Power in Europe by 2020, EWA, 5.

[5] Ataş, C., Avci, B. and Yilmaz, T.H. (2012) Wind Turbine Blade Design and Analysis Graduation Project. Dokuz Eylül University, Faculty of Engineering, 5-8.

[6] Adim, C. and Celiktas, C. (2009) Wind Energy. Master Thesis, 7-29.

[7] Siemens Company (2014). http://siemens.com.tr/

[8] A Framework for Offshore Wind Energy Development in the United States (2005). http://www.usowc.org/pdfs/final_09_20.pdf

[9] (2012) Marine and Offshore Energy. Karim Marketing Report, 7-13.

[10] (2014) Study of the Benefits of a Meshed Offshore Grid in Northern Seas Region. Final Report, 31.

[11] Economic Indicators of Malta (2014). http://www.mfa.gov.tr

[12] Görgün, T. (2008) Renewable Energy Sector. Renewable Energy and Technology, 6-20. http://www.solar-bazaar.com/menuis/igeme-yenilenebilir_enerjiler-teknolojileri..pdf

[13] (2013) Small Island Developing. United Nations Development Projects, 12-13.

[14] Taşhan, E.H., Akdağ, C.T. and Savidis, S. (2010) Tekil Kazık Temel Sisteminin Tek Raylı Yatay Yükler Altındaki Davranış1, 2-3.

[15] British Wind Energy Association (2014) Prospects for Offshore Wind Energy. A Report Written for the EU by BWEA, 7-8. http://www.offshorewindenergy.org/reports/report_026.pdf

[16] Temporary Rural Development Plan for the Turkish Cypriot Community (2010).

[17] Turkish Republic of Northern Cyprus, Ministry of Agriculture and Natural Resources, Department of Statistical and Planning (2010).

[18] Zootekni (2006) Course Handouts from Anadolu University Open Faculty Education.

[19] Koçar, G. (2014) Biomass Definition, Operating of Resources and Characterization, 2014 Winter School. 
[20] Alibaş, K. and Kudal, F. (1988) What Is Biogas? How to Obtain? Where Is It Used. Farmers and Village World Monthly Journal, 4, 25-27.

[21] Erdoğan, C., Seçgin, B. and Demirbilek, R. (2008) Renewable Energy. Research Project in Field Education, 3-17. http://www.yildiz.edu.tr/ oscg/AlanegitimindeBitirmeProjeleri/YenilenebilirEnerjiler.pdf

[22] TRNC Embassy of Turkey (2013) Committee of Help and Aid Report, 1.23.

[23] T.C. Meteroloji Genel Müdürlüğü.

[24] Mor, A. and Çiftçi, D.M. (2006) Economic Activities the Turkish Republic of Cyprus. Firat University Journal of Social Science, 16, 42-44. http://web.firat.edu.tr/sosyalbil/dergi/arsiv/cilt16/sayi1/33-61.pdf 